\title{
Tsafon
}

Revue d'études juives du Nord

$74 \mid 2017$

La Déclaration Balfour, vers l'État d'Israël ?

\section{Jacques Canet et Claude Nataf (sous la direction de), La synagogue de La Victoire, 150 ans de judaïsme français}

Danielle Delmaire

\section{(2) OpenEdition}

Journals

Édition électronique

URL : https://journals.openedition.org/tsafon/435

DOI : $10.4000 /$ tsafon.435

ISSN : 2609-6420

Éditeur

Association Jean-Marie Delmaire

Édition imprimée

Date de publication : 1 décembre 2017

Pagination : 170-174

ISSN : $1149-6630$

\section{Référence électronique}

Danielle Delmaire, « Jacques Canet et Claude Nataf (sous la direction de), La synagogue de La Victoire, 150 ans de judaïsme français », Tsafon [En ligne], 74 | 2017, mis en ligne le 31 mai 2018, consulté le 24 juin 2021. URL : http://journals.openedition.org/tsafon/435 ; DOI : https://doi.org/10.4000/tsafon.435

Ce document a été généré automatiquement le 24 juin 2021.

Tsafon. Revues d'études juives du Nord 


\title{
Jacques Canet et Claude Nataf (sous la direction de), La synagogue de La Victoire, 150 ans de judaïsme français
}

\author{
Danielle Delmaire
}

\section{RÉFÉRENCE}

Jacques Canet et Claude Nataf (sous la direction de), La synagogue de La Victoire, 150 ans de judaïsme français, Paris, édition Porte Plume, 2017, 489 p., $85 €$.

1 En 2015, le Consistoire de Paris et le Consistoire central fêtaient les 140 ans de l'ouverture de la grande synagogue de Paris rue de la Victoire et les 150 ans de la décision de sa construction par un décret impérial de Napoléon III qui autorisait le préfet Haussmann à la prévoir dans l'aménagement du quartier. Pour ces deux anniversaires, les responsables de la communauté de la synagogue de La Victoire ont pris l'initiative de rassembler les contributions d'historiens, les souvenirs de membres éminents du judaïsme parisien afin de produire un magnifique ouvrage sur la plus grande synagogue de France, symbole de l'ensemble du judaïsme français et représentative du franco-judaïsme. C'est en ce lieu que se sont déroulées, et se déroulent encore, les manifestations officielles touchant les communautés juives de France, à l'instar finalement de Notre-Dame de Paris pour les catholiques. C'est là encore que les présidents du Consistoire central, que les grands rabbins de France ou de Paris siègent et prennent la parole, ou reçoivent les personnalités politiques de France et d'Israël. Comme le rappelle Joël Mergui, président du Consistoire central, la synagogue symbolise la réussite de l'intégration du judaïsme dans la cité et de sa place dans la Nation. En effet, l'édifice monumental n'est plus caché, ni trop ostentatoire selon le vœu de la très catholique impératrice Eugénie, et de nombreux détails architecturaux ou décoratifs expriment l'attachement des juifs à la France et à son 
régime républicain. Selon le grand rabbin Haïm Korsia, elle raconte une « histoire d'amour entre le judaïsme et la France ».

2 La publication est une réussite, même si l'on peut déplorer des coquilles voire quelques erreurs (Samuel Cohen pour Samuel Cahen par exemple), de temps à autre une mise en page peu rigoureuse et/ou l'absence de légende près des photos. Elle offre au lecteur un épais et grand volume de 500 pages, sur un luxueux papier glacé ce qui explique son prix élevé. Les articles sont abondants, de longueur et de qualité différentes mais nul n'avait la prétention, semble-t-il, de faire œuvre scientifique à la pointe des dernières découvertes. Pour tous, il s'agissait de rendre hommage à la synagogue, à sa communauté et aux responsables du lieu et des personnes. Les témoignages et les souvenirs constituent une source pour d'autres travaux.

3 Il faut insister sur la qualité des photos, dignes d'un album d'artiste. Les gros plans permettent d'admirer des détails invisibles au visiteur: des sculptures, des versets sculptés, des vitraux et des rosaces, des médaillons, de merveilleuses mosaïques, des boiseries et autres meubles. S'y ajoutent d'anciennes ou d'actuelles photos de cérémonies, de personnages: les illustrations sont abondantes pour le bonheur du lecteur. Parfois, elles s'étalent sur deux pages d'un format supérieur au A4 pour chacune d'elles.

4 Avant de présenter l'édifice, C. Nataf résume les étapes de l'intégration des juifs au long du XIX ${ }^{e}$ siècle français qui les a vu devenir citoyens français et faire partie de la Nation. De la Révolution émancipatrice à la naissance de la III ${ }^{e}$ République, s'est mis en place un franco-judaïsme qui atteste la normalité de la présence juive en France au même titre que le catholicisme ou le protestantisme. C'est dans ce contexte historique que l'édification monumentale de la synagogue devient l'aboutissement du processus d'intégration du judaïsme dans le paysage religieux de la France. Nelly Singer, auteure par ailleurs d'une recherche sur la synagogue de La Victoire, évoque les raisons de la décision impériale d'élever un tel édifice : les autres synagogues parisiennes, érigées pour la plupart durant ce xIX ${ }^{\mathrm{e}}$ siècle, devenaient insuffisantes pour accueillir les juifs dont le nombre ne cessait de s'élever dans la capitale ${ }^{4}$. Le projet fut confié à l'architecte Aldrophe, proche de quelques riches familles juives de Paris qui contribuèrent, partiellement, au financement de la construction. L'Empereur Napoléon III, souvent favorable au judaïsme, apporta son soutien au projet, qui entrait dans sa politique de grands travaux qui bouleversèrent Paris, par amitié envers des industriels ou financiers juifs qui l'aidaient dans cette politique, tels les Rothschild, les Fould, les Pereire pour ne citer qu'eux. Le chantier débuta en 1865 mais il fut interrompu par la guerre de 1870-1871 et la synagogue ouvrit au public dix ans plus tard. Sa monumentalité et sa magnificence permettent de la comparer à une cathédrale, avec ses arcs, ses larges allées, ses vitraux évoquant, sans les représenter physiquement, les grandes figures bibliques. Comme pour les vitraux et les sculptures des églises, la décoration veut communiquer un message édifiant. De splendides photos mettent en valeur cette décoration peu accessible autrement.

5 Hervé Roten, grand spécialiste de la musique juive, offre un article fouillé d'une trentaine de pages et bien illustré sur les chants, les chœurs et les orgues qui ritualisent de plus en plus les offices. Ainsi apparaît un « culte musical consistorial » pour lequel se sont illustrés plusieurs musiciens, chefs de chœur (d'hommes et femmes parfois) et compositeurs de musique liturgique dont le plus connu est Léon Algazi. Le samedi, l'orgue était joué par un non-juif pour ne pas déroger aux prescriptions religieuses 
mais ces habitudes, venues du courant libéral, furent remises en question par de jeunes juifs en 1968. L'introduction de cette musique liturgique, particulière à la France, fait partie, elle aussi, de la constitution d'un franco-judaïsme.

6 L'historienne Béatrice Philippe rappelle les épreuves que dut affronter la communauté juive de France dont elle sortit grandie, finalement. La fin du XIX et au début du $\mathrm{xx}^{\mathrm{e}}$ siècle, soit durant les premières décennies de la synagogue de La Victoire, ces combats furent menés par le grand rabbin Zadoc Kahn : l'affaire Dreyfus, la séparation des Églises et de l'État, la naissance d'un judaïsme libéral avec l'Union libérale du grand rabbin Louis-Germain Lévy, présentée par Catherine Poujol. C. Nataf n'oublie pas la complaisance de Zadoc Kahn à l'égard des nouvelles idées sionistes qui irritaient nombre de responsables communautaires. Les historiens s'accordent pour évoquer un «âge d'or» du franco-judaïsme durant cette période. Un portrait du grand rabbin Zadoc Kahn complète ces pages : il fut un guide incontestable pour ses coreligionnaires qu'il fit accéder à la beauté des récits bibliques grâce à la traduction de la Bible, dite de Zadoc Kahn, il fut également un grand érudit qui participa à la mise en place de la savante Société d'études juives et de sa revue qui toutes deux existent toujours.

7 La grande synagogue était ouverte à tous mais la grande bourgeoisie juive de Paris la fréquentait de manière privilégiée et la choisissait pour y célébrer les événements familiaux et particulièrement les mariages. Cyril Grange, qui a abondamment étudié la grande bourgeoisie juive parisienne (lire notre recension de son ouvrage dans ces mêmes pages), décrit les mariages les plus huppés qui rassemblaient la haute société juive et non juive.

8 Il revient à Philippe Landau, archiviste du consistoire et historien de l'engagement des juifs dans la défense de la France lors de la Grande Guerre, d'écrire les pages du chapitre "D'une guerre à l'autre ». Sauver la patrie s'imposait aux juifs de France et leur sacrifice se doublait d'un autre: accepter l'alliance avec la Russie pogromiste, condamnée par ces mêmes juifs de France, avant la guerre. À ce sacrifice, s'associait un autre renoncement: l'héritage allemand de plusieurs grandes familles juives. L'amour pour la France primait toutes ces réticences et, souligne P. Landau, des juifs alsaciens et lorrains des régions allemandes ont déserté pour rejoindre la France. L'abnégation des soldats juifs, comme celui des rabbins tel Jacob Kaplan, fut à la hauteur de leur reconnaissance envers leur patrie. En témoignent le Mémorial de Douaumont (magnifique photo) « aux Français alliés et volontaires étrangers israélites morts pour la France, 1941-1918 » ainsi que le Monument aux morts érigé à la synagogue de La Victoire par la communauté de Paris. S'y ajoute une plaque en hommage au catholique grand ami des juifs, Charles Péguy, voulue par sa veuve.

9 Entre les deux guerres, c'est dans la synagogue de La Victoire que se sont déroulées toutes les manifestations patriotiques comme celle de 1936 pour laquelle le grand rabbin Kaplan, ancien combattant, accueillit, en juin 1936, les Croix-de-Feu, mouvement de droite mais nullement antisémite. Suivent les biographies des grands rabbins qui ont animé la communauté de La Victoire : Jacques-Henri Dreyfuss, Israël Levi, Maurice Liber qui après-guerre créa L'Amandier fleuri, publication éphémère, hostile au sionisme, Julien Weill et Isaïe Schwartz.

10 Avec ces deux derniers commencent le récit des années noires de la Seconde Guerre mondiale. Grâce au courage et à la volonté audacieuse du grand rabbin Julien Weill sur lequel pesaient de lourdes menaces, le culte ne cessa jamais à La Victoire, durant l'Occupation. L'office du 11 novembre fut maintenu et la communauté ne manqua pas 
de matzot pour la Pâque, le Talmud Torah fut maintenu et quelques bar mitzvah furent célébrées. Ce fut une résistance spirituelle qui animait le grand rabbin et les quelques membres de sa communauté qui pouvaient le suivre. Outre la mortelle déportation, les attentats mettaient en danger les juifs qui fréquentaient encore la synagogue. Celle-ci fut très endommagée en octobre 1941 et en juillet 1942, quatre jours après la grande rafle! Les photos de l'époque et des documents de la police attestent les dégâts, des sifré torah sont détruits.

11 La Libération apporta la présence et le soutien des soldats juifs américains qui fréquentèrent La Victoire: hommage est rendu à Judah Nadich qui eut à cœur de perpétuer le culte dans la grande synagogue malgré les bouleversements de l'immédiat après-guerre ${ }^{5}$. Et très vite, des cérémonies eurent lieu en mémoire des déportés. Laura Hobson Faure insiste sur l'aide américaine qu'elle nomme "le plan Marshall juif». Après-guerre, de "nouvelles problématiques » s'imposaient aux responsables religieux et laïques de la communauté : gérer la destruction et la reconstruction, prendre en charge les rescapés de la Shoah, se positionner vis à vis du nouvel État d'Israël, accorder un rôle, mais lequel, au CRIF créé pendant la guerre, définir la représentation du Consistoire, enfin élaborer de nouvelles relations avec les Églises chrétiennes. C'est alors la longue période du grand rabbinat de Jacob Kaplan qui commence. L'actuel grand rabbin de France, Haïm Korsia qui fut son élève et qui lui a consacré une thèse en histoire, lui rend un vibrant hommage. Et Jacob Kaplan le mérite car il sut défendre sa communauté de France avec l'affaire Finaly, répondre à la fameuse phrase du général de Gaulle qui accusait le peuple juif de domination etc. À ce témoignage s'ajoute celui de son fils.

Cette période est aussi celle des Rothschild très présents dans l'administration de La Victoire et des consistoires: Robert, Guy, Alain. Une généalogie de trois fils du fondateur de la famille française : Alphonse, Gustave et Edmond permet au lecteur de suivre les liens de parenté qui unissent ces personnalités. Le rôle de l'Alliance israélite universelle n'est pas oublié. Jean-Claude Kuperminc, archiviste et historien de l'association, montre l'importance de la famille Leven dans la protection des communautés juives en général et la défense du franco-judaïsme en particulier. Elle aussi œuvre depuis plus de 150 ans! Pour cette période, se succèdent également les biographies des grands rabbins de Paris : Alain Goldman, Meyer Jaïs qui fut aussi rabbin des jeunes, André Chekroun, David Messas; des huissiers comme Oscar Berg (qu'un Allemand pendant la guerre laissa tranquille car sa carte portait le nom de O. Berg!), des responsables de la jeunesse comme Jean-Paul Bader ou des présidents de la communauté de La Victoire comme Stourdzé. Le rabbin Josy Eisenberg bénéficie aussi de quelques pages puisqu'il servit à La Victoire en plus de créer et animer (actuellement encore) l'émission télévisée «La source de vie » ${ }^{6}$. Gilles Bernheim n'est guère oublié sans qu'il soit fait allusion à ses déboires.

Pour cette fin du xxe siècle, une étude de l'historien Ariel Danan présente les relations de la communauté avec l'État d'Israël. Dans les premières années qui suivirent la création de l'État, le consensus n'existait pas, la communauté se divisait même entre partisans et adversaires de cette création. La crainte de perdre la spécificité du francojudaïsme rendait frileux des responsables comme Georges Worsmer et il fallut la diplomatie d'un Alain de Rothschild pour apaiser les dissensions. L'unanimité vint après le succès de la guerre des Six Jours, en juin 1967, et La Victoire accueillit même le grand rabbin des armées israéliennes, Goren. 
L'accueil des juifs expulsés des pays arabes, en 1956, se concrétisa par l'installation d'un oratoire égyptien et d'un oratoire tunisien dans l'enceinte même de la synagogue. La contestation de mai 1968 n'épargna pas les administrateurs de la synagogue de La Victoire qui se virent reprocher un certain laxisme dans le rituel, en acceptant les orgues et les chœurs. Selon les dignitaires de la synagogue, les bases du francojudaïsme risquaient d'être ébranlées mais ils finirent par admettre un peu plus d'orthodoxie. Sont encore exposés les rôles du président Moïse Cohen et des grands rabbins Sirat, notamment son implication décisive dans le développement de l'enseignement de l'hébreu, langue vivante, dans les établissements non privés, et du grand rabbin Sitruk, ces deux derniers rabbins issus du monde séfarade pour les premières fois.

Enfin une étude très fouillée sur «le difficile maintien d'une tradition consistoriale d'ouverture » est signée par la sociologue des communautés juives de France, Martine Cohen. Elle y évoque le changement dans les offices, l'évolution de la place des femmes dans la communauté et de leur prise de responsabilités, le positionnement parfois difficile vis à vis de la double allégeance : à la France et au soutien à l'État d'Israël.

L'ouvrage se termine avec de nombreuses biographies de rabbins et administrateurs ou serviteurs de La Victoire qui n'ont pas été cités dans les articles précédents, des pages qui constituent un petit dictionnaire biographique des personnalités juives de Paris.

Le lecteur a entre les mains un monument livresque qui évoque 150 ans d'un monument architectural et cultuel. Il y trouve une abondance de photos qui fixent des détails sur l'architecture et une abondance d'études et de témoignages sur les hommes et même les femmes qui ont fait vivre la communauté de La Victoire. Un livre luxueux et coûteux mais qui mérite d'être placé dans toutes les bibliothèques, privées ou publiques, qui s'intéressent à l'histoire du judaïsme en France aux $\mathrm{XIX}^{\mathrm{e}}$ et $\mathrm{Xx}^{\mathrm{e}}$ siècles et même à l'histoire religieuse en général.

\section{NOTES}

4. Rappelons qu'une évolution similaire de la communauté lilloise explique l'édification, vingt ans plus tard, de l'actuelle synagogue de Lille.

5. Ici encore, il faut ajouter que des soldats juifs américains ont beaucoup aidé les communautés à se restaurer au lendemain du désastre, ce fut le cas par exemple à Lille.

6. Son émission du 11 juin 2017 fut d'ailleurs consacrée à ce livre sur la synagogue de La Victoire. 